\title{
Birthweight and blood pressure among children in Harare, Zimbabwe
}

\author{
Godfrey Woelk, Irvin Emanuel, Noel S Weiss, Bruce M Psaty
}

\begin{abstract}
Aim-To determine whether poor uterine growth may be associated with increased blood pressure and subsequent hypertension in adulthood.

Methods-A retrospective cohort study of 756 schoolchildren (mean age 6.5 years) was carried out in six low income areas in Harare city, Zimbabwe. Indices of intrauterine growth and blood pressure were assessed.

Results-Adjusted for current weight, the children's systolic blood pressure was inversely related to their birthweight; for each decreasing kg of birthweight, systolic blood pressure rose by $1.73 \mathrm{~mm} \mathrm{Hg}(95 \%$ CI; 0.181 to 3.28). After adjustment for current weight, systolic blood pressure was also inversely associated with occipito-frontal circumference, but not with birth length or gestational age. Diastolic blood pressure was not associated with any of the intrauterine indices. Conclusion-Fetal size may be inversely related to systolic blood pressure in childhood in an African population.

(Arch Dis Child Fetal Neonatal Ed 1998;79:F119-F122)
\end{abstract}

Keywords: intrauterine growth indices; blood pressure; Africa; adult health

In Africa ischemic heart disease is rare but cerebrovascular disorders are common. ${ }^{1}{ }^{2}$ Estimates of the prevalence of hypertension in adults have ranged from $2 \%$ to $41 \%$, with a recent study finding the prevalence in two West African countries to be between 15 and $23 \%{ }^{4}$ The epidemiology of hypertension in Africa seems to be different from that in industrialised countries. In Africa hypertension occurs at a younger age and it rapidly generates significant morbidity and mortality from cerebrovascular disease. ${ }^{5}$

Recent articles have suggested that low birthweight and intrauterine growth retardation may be risk factors for subsequent raised blood pressure and hypertension in adulthood. ${ }^{6-9}$ These findings and the hypothesis are of particular interest in Africa, as the prevalence of low birthweight is about $15 \% .{ }^{10}$ Furthermore, almost all the studies on the birth weight-blood pressure association have been carried out in industrialised countries, and findings in this setting may not be applicable to other regions, and to Africa in particular. Hypertension in Africa has also become more prevalent over the past three decades, ${ }^{1}$ associated with increased urbanisation and Westernisation. ${ }^{2}$ Given that blood pressure rises in an individual with age ${ }^{11}$ a study was developed to assess the relation of birthweight and other birth measures with blood pressure among children in their first year of school and their mothers in Harare, Zimbabwe.

\section{Methods}

In 1994 data were collected in all 42 government primary schools in six of the nine low income suburbs in Harare City, after permission had been obtained from the Ministry of Education and Culture, and from the school authorities. Meetings were called by the school authorities, at which the research team explained the study and invited parents of children in their first year of school (Grade 1) to participate. Those who agreed to do so (94\%), signed consent forms.

Children who were born in Harare, and whose parents had consented, were assembled in a room, usually a classroom, to have their heights, weights, head circumferences, blood pressures and pulses measured. Before having their blood pressures taken, the children were made to sit quietly. The children's blood pressures were taken supine, with an appropriate child sized cuff on the right arm which covered $50 \%$ of the upper arm. Three blood pressure measurements were taken, each of them two minutes apart, using a Dinamap model 8100 portable blood pressure monitor. Systolic, diastolic, mean arterial pressures and pulse were recorded. Heights were measured in metres using a height measuring board, and weights in kilometres using a SECA model 770 portable electronic scale. The children were weighed in light clothing without shoes, standing squarely on the scale, not holding on to any object for support. The height measurements were taken in a standard way. ${ }^{12}$ Head circumference was measured with a tape measure, ensuring that the longest part of the back of head was incorporated. The children who were absent at the time of the examination were included if the team returned to that school the next day. Blood pressures and anthropometric measurements took place mostly in the mornings, during normal school hours.

Birth data were abstracted from the birth registers at the various maternity centres where the study subjects had been born, and from the child health record cards which are kept by mothers. The child health card is prerequisite for school entry, as it has a record of the childhood immunisations. The following data were abstracted from these records on to a form designed for the purpose: birth date, child's sex, birthweight $(\mathrm{kg})$, birth length $(\mathrm{cm})$, occipito-frontal circumference $(\mathrm{cm})$ and gestational age (weeks). 
Table 1 Children's blood pressure, pulse rate, age, birth and anthropometric data

\begin{tabular}{llll}
\hline & Boys mean $(S D)[n]$ & Girls mean $(S D)[n]$ & Total mean $(S D)[n]$ \\
\hline Age (years) & $6.50(0.62)[318]$ & $6.40(0.63)[318]$ & $6.45(0.63)[636]$ \\
Birthweight (g) & $3065.29(534.35)[288]$ & $2985.29(479.95)[295]$ & $3024.81(508.69)[583]$ \\
Birth length (cm) & $49.09(2.46)[1.31]$ & $48.40(2.77)[142]$ & $48.73(2.45)[273]$ \\
OFC (cm) & $35.09(1.87)[133]$ & $34.56(1.88)[144]$ & $34.82(1.89)[277]$ \\
Weight (kg) & $20.41(2.48)[384]$ & $19.69(2.86)[372]$ & $20.06(2.69)[756]$ \\
Height (cm) & $115.94(5.97)[383]$ & $115.02(5.63)[372]$ & $115.49(5.82)[755]$ \\
Head circumference (cm) & $52.59(1.44)[379]$ & $51.51(1.54)[371]$ & $52.06(1.58)[750]$ \\
BMI (wt/ht $\left.{ }^{2}\right)$ & $15.21(1.50)[382]$ & $14.83(1.64)[372]$ & $15.02(1.58)[754]$ \\
Systolic blood pressure (mm Hg) $_{\text {Diastolic blood pressure (mm Hg) }}$ & $108.27(9.08)[386]$ & $108.39(9.62)[370]$ & $108.33(9.34)[756]$ \\
Pulse (bpm) & $61.57(8.75)[386]$ & $62.74(9.08)[369]$ & $62.14(8.93)[755]$ \\
& $87.63(12.41)[386]$ & $92.95(12.73)[370]$ & $90.24(12.84)[756]$ \\
\hline
\end{tabular}

$t^{\star}=5.824, \mathrm{p}<0.001$ between boys and girls.

OFC: occipito-frontal circumference; BMI: body mass index; SD: standard deviation.

The data were entered and analysed on Epi Info (version 6) and SPSS/PC+ computer software. Where there were differences in the data between the three types of records (the birth registers, the child health card, and the individual maternal record), the birth register was taken as the standard. Systolic, diastolic, and pulse measurements were averaged over the last two readings for the children. Birthweights were assessed from records, and where these were not available, from the mothers' reports. Eleven per cent of the birthweights were from the mothers' reports. When mothers' responses were compared with the recorded birthweights, $397(75.3 \%)$ of the responses corresponded with the record. Among those that were discordant, there was a mean difference of $-31.24 \mathrm{~g}$ (SD 319.3) on the mothers' birthweight responses, compared with the records.

Statistical analyses included analysis of variance and multiple linear regression techniques. Birthweight, birth length, current weight, height and gestational age were entered into the regression models as continuous variables. Twins were excluded from the analysis.

\section{Results}

Of 772 children sampled in 42 schools throughout Harare (including the 16 twins which have been excluded from this analysis), $583(77.1 \%)$ had their birthweights ascertained (from either the records or the mothers' reports), and $636(84.1 \%)$ had their ages recorded. Table 1 shows the children's blood pressure, age, pulse rates, birth and anthropometric data. Only about $36 \%$ of the children had their birth lengths and occipito-frontal circumferences ascertained, and only the records of $240(31.7 \%)$ gestational ages were found.

\section{BIRTH WEIGHT}

Blood pressure

Table 2 shows mean systolic and diastolic pressures by $500 \mathrm{~g}$ intervals of birthweight, adjusted for current weight. The data are pooled as there was no gender difference in the blood pressures. As current weight was so strongly positively associated with blood pressure, $(p<0.001)$, it was necessary to control for this to assess the birthweight-blood pressure correlation.

Children in the highest birthweight category had the lowest mean systolic and diastolic blood pressures, while those in the other three categories (2500-3499 g) had levels somewhat similar to one another. When analysed as a continuous variable, birthweight was significantly inversely associated with systolic blood pressure $(p=0.0286)$, adjusted for current weight. For each decreasing kg of birthweight, systolic blood pressure rose by $1.73 \mathrm{~mm} \mathrm{Hg}$ (95\% CI; 0.182 to 3.28). A formal test for interaction of current weight and birthweight, proved negative $(p=0.15)$. The sex and age of the child were not found to be confounders of the birth weight/blood pressure association. There was no association with diastolic blood pressure after adjustment for current weight, though the regression coefficients were also negative, $-1.06 \mathrm{~mm} \mathrm{Hg} / \mathrm{kg}$ birthweight (95\% $\mathrm{CI} ;-2.573$ to 0.452 ).

Pulse rate

The mean pulse rates by $500 \mathrm{~g}$ intervals of birthweight adjusted for sex are also shown in table 2. Pulse rate exhibited a similar trend to blood pressure; children whose birthweight was in the heaviest category had the lowest pulses, while those in the second lightest birthweight category had the highest pulse rates. The pulse rates of the heaviest children were, on average, 4.64 beats per minute slower than those in the second lightest category of birthweight.

When run as a continuous variable, and adjusted for sex, birthweight was significantly inversely associated with pulse rate $(p=0.0015)$. For each decreasing kg of birthweight, pulse rate rose by 3.2 beats per minute (95\% CI; 1.24 to 5.23 ).

Table 2 Association between systolic (SBP) and diastolic (DBP) blood pressure ( $\mathrm{mm} \mathrm{Hg}$ ), and birthweight (500 $\mathrm{g}$ intervals), adjusted for current weight ( $\mathrm{kg}$ ), and between pulse rate (bpm) and birth weight, adjusted for sex

\begin{tabular}{lllllll}
\hline Birthweight $(g)$ & $\begin{array}{l}\text { No of } \\
\text { subjects }\end{array}$ & Mean SBP (mm Hg) & $\begin{array}{l}\text { No of } \\
\text { subjects }\end{array}$ & Mean DBP (mm Hg) & $\begin{array}{l}\text { No of } \\
\text { subjects }\end{array}$ & Mean pulse rate (bpm) \\
\hline$<2500$ & 73 & 94.49 & 73 & 52.69 & 71 & 83.84 \\
$2500-2999$ & 168 & 95.29 & 167 & 55.29 & 159 & 84.20 \\
$3000-3499$ & 231 & 94.06 & 231 & 53.44 & 224 & 81.97 \\
$3500+$ & 104 & 91.87 & 104 & 52.53 & 96 & 79.56 \\
Total & 576 & 93.93 (SD 2.46) & 575 & $53.48(\mathrm{SD} 0.77)$ & 550 & 82.39 (SD 2.12) \\
\hline
\end{tabular}


Table 3 Association between means of blood pressure ( $\mathrm{mm} \mathrm{Hg}$ ) and pulse rate, and tertiles of occipito-frontal circumference $(\mathrm{cm})$ adjusted for current weight $(\mathrm{kg})$ and height $(\mathrm{cm})$, (blood pressure) and sex (pulse rate)

\begin{tabular}{lllllll}
\hline OFC $(\mathrm{cm})$ & $\begin{array}{l}\text { No of } \\
\text { subjects }\end{array}$ & Mean SBP $(\mathrm{mm} \mathrm{Hg})$ & $\begin{array}{l}\text { No of } \\
\text { subjects }\end{array}$ & Mean DBP $(\mathrm{mm} \mathrm{Hg})$ & $\begin{array}{l}\text { No of } \\
\text { subjects }\end{array}$ & Mean pulse rate (bpm) \\
\hline$<34$ & 65 & 101.66 & 65 & 64.32 & 65 & 84.75 \\
$34-35$ & 111 & 101.16 & 110 & 64.69 & 111 & 84.27 \\
$36+$ & 100 & 99.29 & 100 & 63.70 & 100 & 83.02 \\
Total & 276 & $100.70($ SD 1.25) & 275 & $64.23(\mathrm{SD} 0.49)$ & 276 & 84.01 (SD 0.89) \\
\hline
\end{tabular}

\section{BIRTH LENGTH}

Blood pressure

There was no association between birth length and blood pressure, adjusted for current weight. Children in the highest tertile of birth length (50 or more $\mathrm{cm}$ ) had the lowest mean systolic pressure of $92.46 \mathrm{~mm} \mathrm{Hg}(\mathrm{n}=98)$, compared with $93.76 \mathrm{~mm} \mathrm{Hg}$ for birth lengths 48-49 $\mathrm{cm}(\mathrm{n}=136)$, and 93.87 for birth lengths of less than $48 \mathrm{~cm}(\mathrm{n}=38)$. The mean diastolic pressures were 58.87, 58.85 $(\mathrm{n}=135)$, and $58.37 \mathrm{~mm} \mathrm{Hg}$, respectively.

\section{Pulse rate}

The pulse rate, adjusted for sex, seemed to decrease by increasing tertile of birth length. Children in the lowest tertile of birth length (less than $48 \mathrm{~cm}$ ) had the highest mean pulse rates of 86.51 beats per minute $(n=70)$, compared with 85.12 beats per minute for birth lengths $48-49 \mathrm{~cm}(\mathrm{n}=104)$, and 82.98 beats per minute for birth lengths of 50 or more $\mathrm{cm}(\mathrm{n}=98)$. When analysed as a continuous variable, birth length was significantly inversely associated with pulse $(\mathrm{p}=0.0104)$, after adjustment for sex. For each $1 \mathrm{~cm}$ increase in birth length, mean pulse rate decreased by 0.78 beats per minute ( $95 \% \mathrm{CI} ; 0.18$ to 1.37 ).

HEAD CIRCUMFERENCE AT BIRTH

(OCCIPITO-FRONTAL CIRCUMFERENCE)

Blood pressure

Adjusted for current weight and height, the systolic and diastolic pressures were lowest in the highest tertile of OFC, with the mean systolic pressure decreasing with each increasing tertile of OFC (table 3). When entered into the model as a continuous variable, systolic blood pressure was inversely associated with head circumference at birth $(\mathrm{p}=0.0245)$, controlling for current height and weight. For each $1 \mathrm{~cm}$ increase in OFC, mean systolic blood pressure decreased by $0.66 \mathrm{~mm} \mathrm{Hg}(95 \% \mathrm{CI}$; 0.09 to 1.24$)$.

Pulse rate

There was no association between pulse rate and OFC, adjusted for sex, though the highest tertile of OFC had the lowest pulse, and the lowest tertile the highest (table 3 ).

\section{GESTATIONAL AGE}

Blood pressure

There was no association between the means of blood pressure by tertile of gestational age, adjusted for current weight. The mean systolic blood pressures were $91.98 \mathrm{~mm} \mathrm{Hg}$ for the lowest tertile of gestational age of less than 38 weeks ( $\mathrm{n}=51$ ), $89.89 \mathrm{~mm} \mathrm{Hg}$ for those between 38 and 39 weeks ( $n=73)$, and $89.93 \mathrm{~mm} \mathrm{Hg}$ for gestational ages 40 to 44 weeks $(n=116)$. The mean diastolic pressures were $51.78 \mathrm{~mm} \mathrm{Hg}$, $51.713 \mathrm{~mm} \mathrm{Hg}$, and $50.629 \mathrm{~mm} \mathrm{Hg}(\mathrm{n}=115)$, respectively. An analysis was also made of preterm (less than 37 weeks) and term babies. This showed a mean systolic pressure of 90.63 $\mathrm{mm} \mathrm{Hg}$ for the preterm babies, and $90.90 \mathrm{~mm}$ $\mathrm{Hg}$ for those born at term. For the diastolic pressures, these levels were $49.75 \mathrm{~mm} \mathrm{Hg}$ and $50.24 \mathrm{~mm} \mathrm{Hg}$, respectively. There were, however, only 27 preterm babies.

Pulse rate

There was no association between pulse rate and length of gestation, adjusted for sex. The mean pulse rates by tertile of gestational age were 85.73 beats per minute $(n=51), 85.187$ $(n=73)$, and $85.264(n=116)$, respectively.

\section{Discussion}

In summary, we found that birthweight was inversely associated slightly with systolic blood pressure, after adjustment for current weight. Unadjusted, systolic blood pressure rose by only $0.358 \mathrm{~mm} \mathrm{Hg}$ (95\% CI; -1.811 to 1.095$)$, for each decreasing $\mathrm{kg}$ of birthweight. There was no clear association between birthweight and diastolic blood pressure. Current weight is strongly related to externally measured blood pressure, and controlling for current weight implies that we are evaluating the possible relation of birthweight to systolic blood pressure beyond the relation of birthweight to current weight. Birthweight and birth length were also inversely associated with pulse rate. Occipitofrontal circumference was inversely related to systolic blood pressure. Birth length was not associated with blood pressure. Gestational age was unrelated to blood pressure and pulse rate.

The use of a standardised protocol and the same calibrated automated (oscillometric) blood pressure machine throughout the study is likely to have minimised errors in blood pressure measurement. The oscillometric method is considered to be the most accurate and convenient method of indirectly measuring blood pressure..$^{13}$ Birthweight recall bias was likely to have been minimal, as nearly $90 \%$ of birthweights were obtained from the birth records, and this error is likely to have been random, leading to an underestimate rather than an overestimate of the strength of the association with blood pressure. The birthweights and blood pressures were collected at different times, so that in most cases the observers had no knowledge of the birthweight in relation to the blood pressures of individual children. Much of the time, the functions of the records review and the blood pressure monitoring were also carried out by different people.

There is a potential for selection bias as the birthweights for $23 \%$ of the children were not 
ascertained. The large amount of missing data on birth length, and gestational age particularly, is more problematic, not only affecting the power of the study, but potentially introducing bias. To our knowledge, this is the first published study of birthweight in relation to blood pressure in African children. The inverse association with systolic blood pressure is consistent with other studies in children, ${ }^{7914} 15$ adolescents, ${ }^{16}$ and adults. ${ }^{68917}$ The association, however, was not smoothly graded, though not quite the U shaped relation observed by Launer et al. ${ }^{18}$ The size of the association of $-1.73 \mathrm{~mm} \mathrm{Hg} / \mathrm{kg}$ was similar to the $-1.83 \mathrm{~mm} \mathrm{Hg} / \mathrm{kg}$ reported by Whincup, Cook and Shaper. ${ }^{15}$ While the strength of this relation is modest, this association may be progressively amplified in childhood ${ }^{14}$ and later life. ${ }^{17}$ In adults a $1 \mathrm{~kg}$ increase in birthweight is equivalent to a fall in systolic pressure of $5 \mathrm{~mm}$ $\mathrm{Hg} .{ }^{19}$ The finding of a weak non-statistically significant association of birthweight with diastolic blood pressure was also consistent with other studies. ${ }^{9}$ This could be because the spread of the diastolic pressures was less than that of the systolic pressures and because of the greater error in measurement of this variable.

We found only two published reports on the association between pulse rate and birthweight among children of this age, one describing a weak inverse association, ${ }^{9}$ the other, no association. ${ }^{20}$

The finding of the inverse association between head circumference at birth with systolic blood pressure is consistent with that found among children, ${ }^{7}$ and adults. ${ }^{6}$ The inverse association of blood pressure with birthweight and head circumference suggest that the birthweight-blood pressure relation is primarily due to total fetal growth rather than the rate of growth.

A hypothesis proposed to explain the inverse relation of birthweight and blood pressure is that of poor nutrition in pregnancy. ${ }^{19}$ This hypothesis is supported by animal experiments ${ }^{2122}$ and a Jamaican study. ${ }^{16}$ Several mechanisms linking fetal growth retardation and increased blood pressure have been proposed. One is an increased concentration of plasma insulin-like growth factor-1 in childhood, ${ }^{23}$ another is maternal iron deficiency anaemia. ${ }^{24}$ It has been been suggested that maternal protein deprivation may lead to higher concentrations of angiotensin converting enzyme. ${ }^{21}$ The higher activities of this enzyme result from the kidney due to intrauterine growth retardation. This hypothesis is similar to that of hypertension being inversely associated with the number of nephrons, and that low birthweight babies have fewer nephrons. ${ }^{25}{ }^{26}$ Other proposed mechanisms have included impaired vascular structure, including loss of elasticity in vessel walls ${ }^{27}$; suboptimal organ development ${ }^{28}$; and increased exposure to blood pressure raising maternal glucocorticoid hormones. ${ }^{29}$

We can only speculate about the findings on the pulse rate. Maternal stress (including under nutrition) may lead to decreased fetal placental circulation, consequent fetal growth retardation, and a faster fetal heart rate because of the stress of insufficient fetal placental circulation.
Further study is needed on the birthweightpulse association, the extent to which it is an indicator of reduced fetal growth, and on whether pulse rate tracks in the same way as blood pressure.

We are grateful to the teachers, parents, and children who participated in this study. We acknowledge Steve Gloyd, Jonathan Matenga, and Warren Gunteroth for their support and comments on the study. The research was funded in part by the Rockefeller Foundation, through their African Dissertation Award Programme, and by the W K Kellogg Foundation.

1 Akinkugbe OO. World epidemiology of hypertension in Blacks. In: Hall DW, Saunders E, Shulman NB, eds. Hypertension in Blacks: Epidemiology, Pathophysiology and Treatment. Year Book Medical Publishers, Chicago, 1985:3-16.

2 Issacson C. The pathology of hypertension in a tropical environment. Clin Cardiol 1983;6:195-8.

3 Nissinen A, Boethig S, Granroth H, Lopez AD. World Health Stat $Q 1988 ; 41: 141-54$

4 Cooper R, Rotimi C, Ataman S, et al. The Prevalence of hypertension in seven populations of West African origin. Am 7 Public Health 1997;87:160-8.

5 Mokhobo KP. Aspects of hypertension among blacks. $S$ Afr Med F 1982;61:929-30.

6 Barker DJP, Godfrey KM, Osmond C, Bull A. The relation of length, ponderal index and head circumference to blood pressure and the risk of hypertension in adult life. Paediatr Perinat Epidemiol 1992;6:35-44.

7 Law CM, Barker DJP, Bull AR, Osmond C. Maternal and fetal influences on blood pressure. Arch Dis Child 1991;66:1291-5.

8 Barker DJP, Bull AR, Osmond C, Simmonds SJ. Fetal and placental size and the risk of hypertension in adult life. BMF 1990;301:259-62.

9 Barker DJP, Osmond C, Golding J, Kuh D, Wadsworth MEJ. Growth in utero, blood pressure in childhood and adult life and mortality from cardiovascular disease. BMF 1989;298:564-7.

10 Martorell R, Gonzalez-Cossio T. Maternal nutrition and birth weight. Yearbook of Physical Anthropology $1987 \cdot 30 \cdot 195-220$

11 Woelk G. Blood pressure tracking from child to adulthood: a review. Cent Afr Med f 1994;40:163-9.

12 United Nations Department of Technical Cooperation for Development and Statistical Office. National Household Survey Capability Programme: How to weigh and measure children. Assessing the nutritional status of young children in household surveys. UN: New York: 1986.

13 Park MK, Menard SM. Accuracy of blood pressure measurement by the DINAMAP monitor in infants and children. Pediatrics 1987;79:907-14.

14 Whincup P, Cook D, Papacosta O, Walker M. Birth weight and blood pressure: cross sectional and longitudinal relations in childhood. BMF 1995;311:773-6.

15 Whincup PH, Cook DG, Shaper AG. Early influences on blood pressure: a study of children aged 5-7 years. BMF 1989;299:587-91.

16 Forrester TE, Wilks RJ, Bennett FI, et al. Fetal growth and cardiovascular risk factors in Jamaican school children. BMF 1996;312:156-60.

17 Law CM, de Swiet M, Osmond C, et al. Initiation of hypertension in utero and its amplification throughout life. BMF 1993;306:24-7.

18 Launer LJ, Hofman A, Grobbee DE. Relation between birth weight and blood pressure: longitudinal study of infants and children. BMF 1993;307:1451-4.

19 Barker DJP. Mothers, Babies and Diseases in Later Life. BMJ Publishing Group, London, 1994.

20 Gillum RF. Resting pulse rate of children aged 1-5 years. $\mathcal{F}$ Natl Med Assoc 1991;83:153-8.

21 Langley SC, Jackson AA. Increased systolic blood pressure in adult rats induced by fetal exposure to maternal low protein diets. Clin Sci 1994;86:217-22.

22 Crowe C, Dandekar P, Fox M, Dhingra K, Bennet L, Hanson MA. The effects of anaemia on heart, placenta and body weight, and blood pressure in fetal and neonatal rats. f Physiol 1995;488:515-19.

23 Fall CHD, Pandit AN, Law CM, et al. Size at birth and plasma insulin-like growth factor-1 concentrations. Arch plasma insulin-like growth

24 Godfrey KM, Barker DJP. Maternal nutrition in relation to fetal and placental growth. Eur 7 Obstet Gynecol Reprod Biol 1995;61:15-22.

25 Mackenzie HS, Brenner BM. Fewer nephrons at birth: a missing link in the etiology of essential hypertension? $\mathrm{Am} f$ Kidney Dis 1995;26:91-8.

26 Brenner BM, Chertow GM. Congenital oligonephropathy and the etiology of adult hypertension and progressive renal injury. Am F Kidney Dis 1994;23:171-5.

27 Martyn CN, Barker DJP, Jesperson S, Greenwald S, Osmond C, Berry C. Growth in utero, adult blood pressure and arterial compliance. Br Heart $\mathcal{F}$ 1995; 73:116-21.

28 Emanuel I. Intergenerational factors in pregnancy outcome. Implications for teratology? Issues and Reviews in Teratology 1992;6:47-84.

29 Edwards CRW, Benediktsson R, Lindsay RS, Seckl JR. Dysfunction of placental glucocorticoid barrier: link between fetal environment and adult hypertension? Lancet, 1993;341:355-7. 